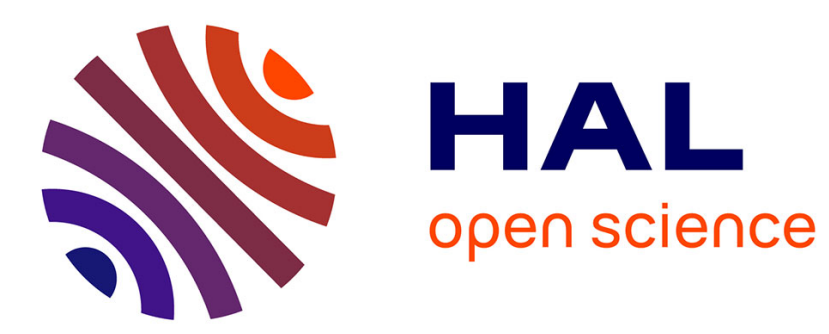

\title{
Recent developments in shallow-depth electrical and electrostatic prospecting using mobile arrays
}

Cédric Panissod, Michel Dabas, Albert Hesse, Alain Jolivet, Jeanne Tabbagh, Alain Tabbagh

\section{- To cite this version:}

Cédric Panissod, Michel Dabas, Albert Hesse, Alain Jolivet, Jeanne Tabbagh, et al.. Recent developments in shallow-depth electrical and electrostatic prospecting using mobile arrays. Geophysics, 1998, 63 (5), pp.1542-1550. hal-02925689

\section{HAL Id: hal-02925689 \\ https://hal.science/hal-02925689}

Submitted on 30 Aug 2020

HAL is a multi-disciplinary open access archive for the deposit and dissemination of scientific research documents, whether they are published or not. The documents may come from teaching and research institutions in France or abroad, or from public or private research centers.
L'archive ouverte pluridisciplinaire HAL, est destinée au dépôt et à la diffusion de documents scientifiques de niveau recherche, publiés ou non, émanant des établissements d'enseignement et de recherche français ou étrangers, des laboratoires publics ou privés. 


\title{
Recent developments in shallow-depth electrical and electrostatic prospecting using mobile arrays
}

\author{
Cédric Panissod*, Michel Dabas ${ }^{\ddagger}$, Albert Hesse**, \\ Alain Jolivet**, Jeanne Tabbagh"** and Alain Tabbagh ${ }^{\ddagger}$
}

\begin{abstract}
Application of mobile electrical and electrostatic quadripoles during the past ten years has allowed a considerable increase in the size of the surveyed areas, together with keeping a high spatial resolution and a reduction of the total cost of a survey. Two new developments of towed arrays are illustrated here: (1) a pole-pole array pulled by the operator provides a lightweight solution for mapping large surfaces at a unique given depth of investigation, as shown by the prospection of the RomanBritish city of Wroxeter; and (2) a multipole, multidepth system allows a 3-D investigation of the ground resistivity, as illustrated by the experiments undertaken on the test site of Garchy and on the archaeological site of Montbaron (Indre, France).
\end{abstract}

\section{INTRODUCTION}

In shallow-depth electrical prospecting for archaeology, pedology, civil engineering, and environmental applications, two major constraints intervene. First, a small measurement mesh must be used to respect a correct spatial sampling where very short variations of the ground resistivity may exist and be of high significance. Second, it is desirable to reduce as much as possible the cost of a survey without limiting the extent of the investigated area. This led us to the development of mobile quadripoles allowing continuous measurement while moving.

The first experiment was achieved more than thirty years ago (Hesse, 1966) in archaeological prospecting with small metallic wheels and analog drawing of the profiles in the field. More sophisticated solutions were studied later, such as the use of liquid high-pressure jets instead of metallic electrodes (Hesse et al., 1986). But the combined use of simple wheels with spikes and a resistivity meter with a very short measurement duration $(<0.01 \mathrm{~s})$ appears to be the most practical. Such a device allows us to oversample the data (typically at a $10-\mathrm{cm}$ sampling step) so that outliers corresponding to a lack of galvanic contact between the ground and a wheel can be rejected (Tabbagh, 1988). This solution has been applied with success during ten years with square arrays (Dabas et al., 1989; Tabbagh, 1992).

The electrostatic method was developed in parallel. It constitutes a generalization to both dielectric and conductive media of the dc electrical method. The electrostatic potential generated by an electrostatic pole, located in the air not far from the ground surface, is dependent on the complex permittivity of the ground (Grard and Tabbagh, 1991). For the common range of soil resistivity and for a sufficiently low frequency $(<100 \mathrm{kHz}$ in practice), resistivity is the dominant term in the complex permittivity. When the poles are lying on ground surface, an electrostatic quadripole delivers the same result and refers to the same theory and modeling methods as classical electrical quadripoles (Tabbagh et al., 1993). This method can be used on any type of ground surface.

After a review of the characteristics of the in-use square arrays, a case study is presented; recent developments are presented thereafter. They are oriented in two different paths:

1) making the array lighter to avoid use of a vehicle (a fourwheel-drive car or an agricultural tractor), the moving poles pulled by the operator, and

2) using heavy multipole systems, called MUCEP (MUltipole Continuous Electrical Profiling), which allow measurements over several depths of investigation to perform an exhaustive 3-D exploration.

Manuscript received by the Editor January 7, 1997; revised manuscript received November 4, 1997.

*Département de Géophysique Appliquée, UMR 7619, Université Pierre et Marie Curie-Paris 6, 4 place Jussieu, 75252 Paris Cedex 05, France; E-mail: cpanissod@ccr.jussieu.fr.

$\ddagger$ Département de Géophysique Appliquée, UMR 7619, Université Pierre et Marie Curie-Paris 6, 4 place Jussieu, 75252 Paris Cedex 05, France and Centre de Recherches Géophysiques, UMR 7619, CNRS, 58150 Garchy, France; E-mail: (Michel Dabas) dabas@ccr.jussieu.fr; (Alain Tabbagh) crg@garchy.cnrs.fr.

**Centre de Recherches Géophysiques, UMR 7619, CNRS, 58150 Garchy, France.

(C) 1998 Society of Exploration Geophysicists. All rights reserved. 


\section{SQUARE ARRAYS}

Figure 1 shows the towed square quadripole commonly used in archaeological and pedological prospecting; it is called RATEAU (Résistivimètre ATtelé à Enregistrement AUtomatique; the English equivalent term is harrow). The square is $1 \mathrm{~m}$ per side, which offers a depth of investigation of the same order. Figure 2 shows the electrostatic square array designed for road applications, where the poles are located inside the tires of the four wheels (Jolivet, 1992). This solution allows the pole to be maintained at a fixed clearance from the ground surface and protects it from obstacles that could damage the poles when the quadripole moves at relatively high speeds $\left(60 \mathrm{~km}-\mathrm{h}^{-1}\right)$. Here, the side of the square measures $1.2 \mathrm{~m}$.

The square configuration has several advantages. It is compact. A pair of electrodes can be designed as an easy-to-move axis, while its width does not exceed that of the towing vehicle. There is no need for an external electrical link to a fixed reference. And its response to resistivity changes exhibits a lower apparent anisotropy than that of classical in-line arrays (Hesse et al., 1986). This technique was applied to a large variety of

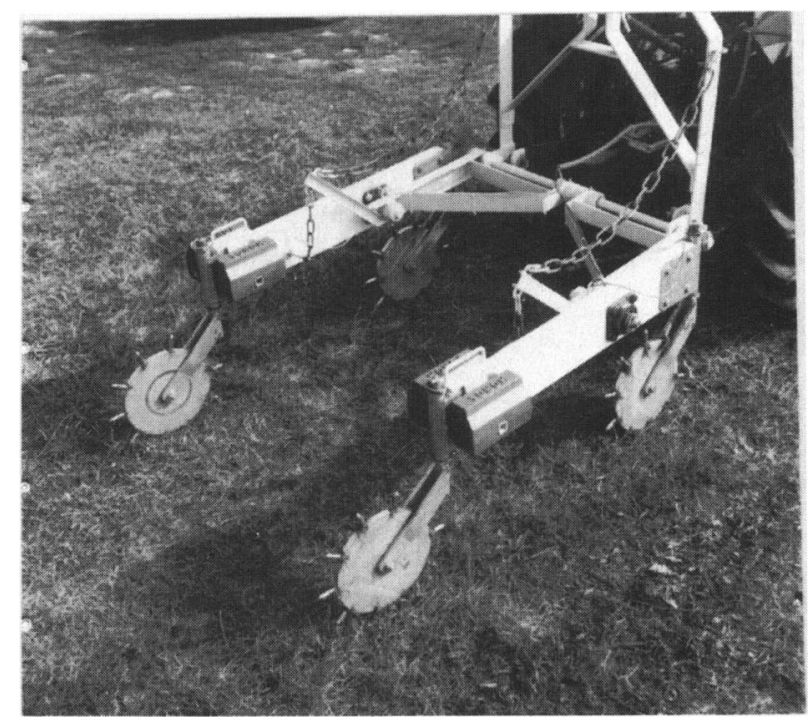

FIG. 1. Towed square quadripole (1-m side) pulled by an agricultural tractor.

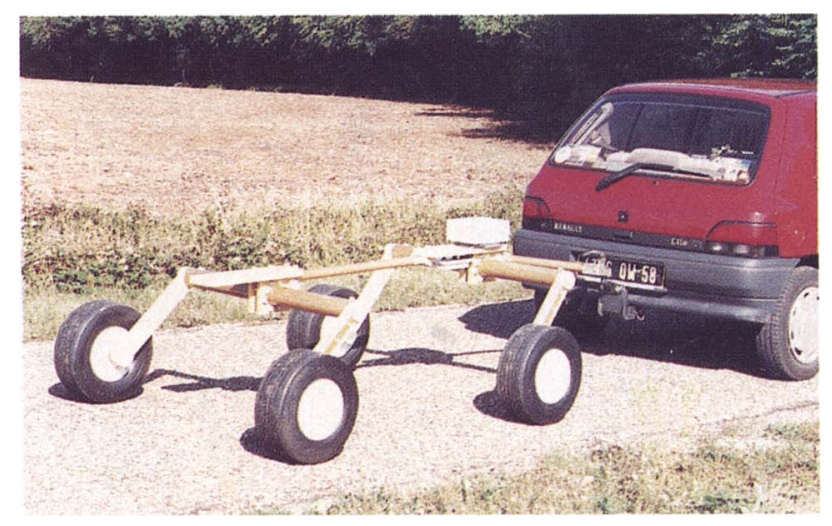

FIG. 2. Electrostatic quadripole designed for road studies where the poles are inside the tires of the wheels $(1.2-\mathrm{m}$-side square array). archeological and pedological studies; we present here the case of the Gallo-Roman site of Champcelée (Suilly-la-Tour, Nièvre, France)

This site corresponds to the remains of a rural temple and its subsidiaries. It is located on a plateau just beside the village on a small topographic summit. On the day of prospecting (March), the soil was plowed and bare with a rough surface. The survey covered a surface of about 3 ha on the same agricultural parcel. Field measurements took two days; the data were acquired on $100-\mathrm{m}$-long, $1-\mathrm{m}$-spaced profiles at a $10-\mathrm{cm}$ sampling rate. The total survey comprised two blocks of 100 -m-long profiles. The data were processed by first rejecting the outliers by median filtering and then resampling at 1-m steps along each profile. The two blocks were then equalized and the global map filtered using a linear directional filter to reject the anomalies parallel to the agricultural work.

The apparent resistivity ranges from 50 to $140 \mathrm{ohm}-\mathrm{m}$ (Figure 3). Among several complex linear features which can not be interpreted without excavations, three square buildings of 15,18 , and $37 \mathrm{~m}$ per side and of N-S and E-W orientation appear as resistive anomalies. The global resistivity change from $200 \mathrm{ohm}-\mathrm{m}$ at the north to $50 \mathrm{ohm}-\mathrm{m}$ at the south corresponds to granularity variations in the decalcification subsoil from gravel to silt and clay.

\section{POLE-POLE MOBILE ARRAY}

To lighten the instrument, the simplest solution is to reduce the number of moving electrodes by adopting the pole-pole array where only one injection electrode, $A$, and one potential electrode, $M$, are mobile; the two others, $B$ and $N$, are fixed at great distances from $A$ and $M$ and separated by a great distance. (This configuration differs from the so-called twin electrodes system where $B N=A N$.) This configuration is of current use in point-by-point measurements (Martinaud, 1990; David, 1995). Because the current distribution around $A$ is isotropic (in uniform or layered ground), the apparent anisotropy effect is limited. The system pulled by the operator is presented in Figure 4; the two spike wheels $1 \mathrm{~m}$ apart are weighted by small metallic masses $(2 \mathrm{~kg})$ and by the small carriage on which are disposed the resistivity meter, the battery, and a PC. A third wheel is used for measuring the distance. A long cable including two thin wires reach the two other poles, $50 \mathrm{~m}$ apart at least. The investigation depth of this array is slightly better than that of a $1 \mathrm{~m} / \mathrm{side}$ square array.

Wroxeter (Shropshire, England) is a large Roman-British city (Viroconium Cornoviorum) that constitutes an archeological reserve (Wroxeter Hinterland Project, University of Birmingham). It is being used as a test site to compare different methods. The land is an uncultivated pasture. The electrical survey was undertaken using the mobile pole-pole. The sampling steps were $0.1 \mathrm{~m}$ along profiles and $1 \mathrm{~m}$ between profiles. The results were resampled at a 1-m step with median filtering. The resistivity map covered a 4-ha area at a fieldwork rate of 5 hours/ha, equivalent if not better than that obtained with a tractor. The results (Figure 5) exhibit a very good map of the remains of the city: three major streets and two large adjacent buildings, together with many other tiny features, are clearly evidenced (in black), the calcareous stones used in the building being more resistive than the surrounding soil. The two thin conductive lines (in white) correspond to filled-in gas pipeline trenches (the steel pipes generate much greater disturbances 
on the magnetic map), and the most conductive circles correspond to farming artifacts. The relatively high value of the global resistivity, particularly in the central area of the map, is because of the sandy nature of the soil.

\section{MUCEP ARRAYS}

In electrical prospecting, the use of multipole arrays aims at investigating in both vertical and horizontal directions simul- taneously. The most common type of multipole is the panel, where a series of electrodes is placed along the same line and switched following a predefined protocol. A complete survey of a given area can be complemented by a series of parallel panels. However, panel installation is a rather long task. In conditions where the presence of water facilitates galvanic contacts, such a panel can be pulled (Martiré, 1996) and an identical protocol of measurement can be used. For in-field measurements, however, the line of pulled electrodes a)

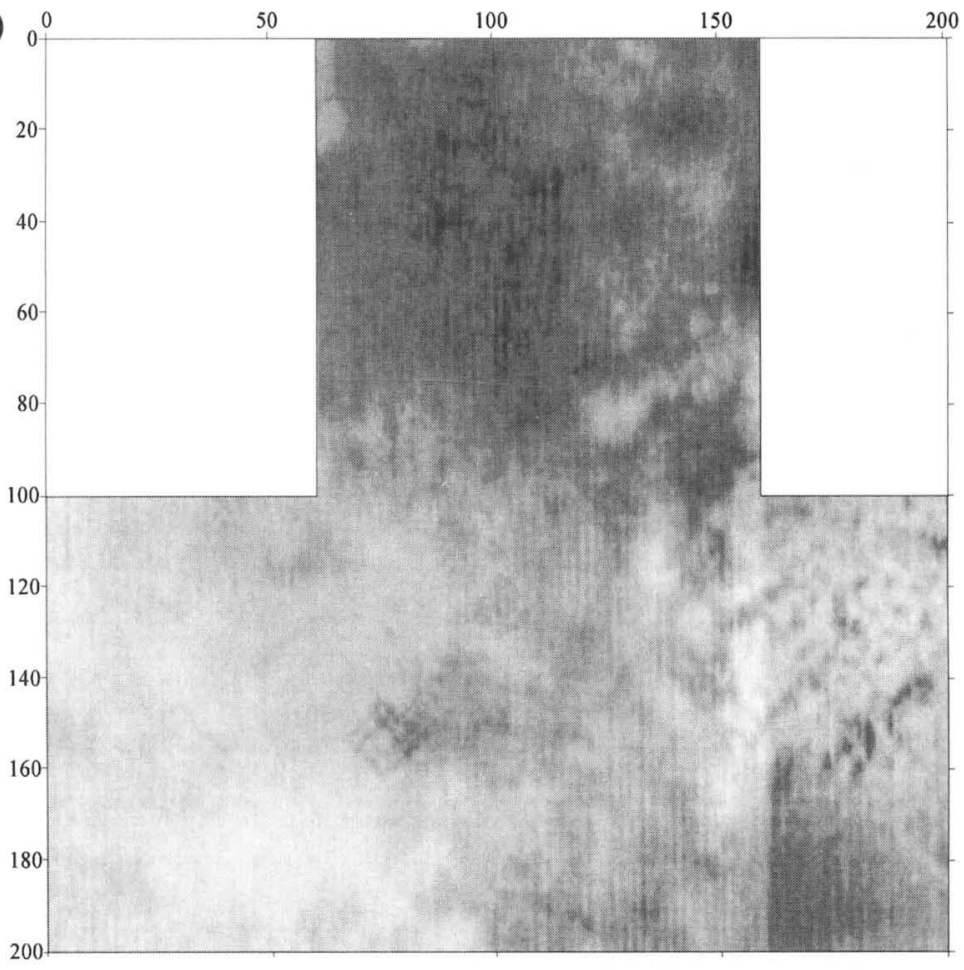

b)

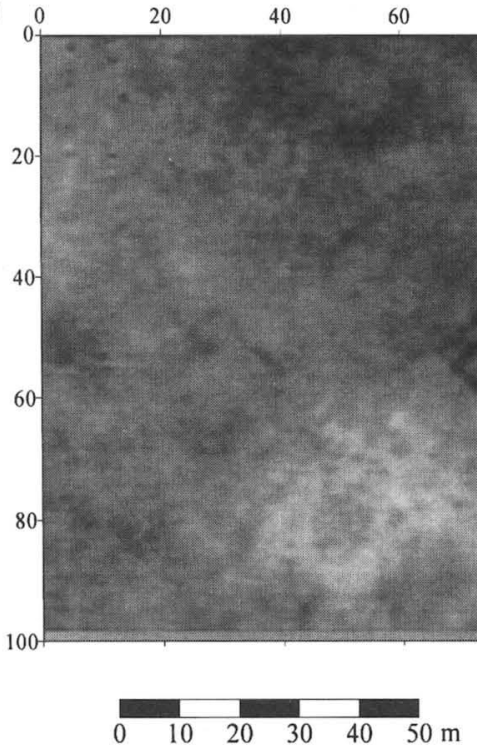

$\rho \mathrm{a}$
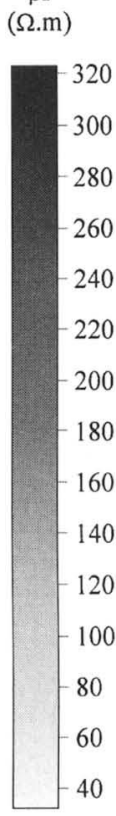

$\rho a$
$(\Omega . m)$

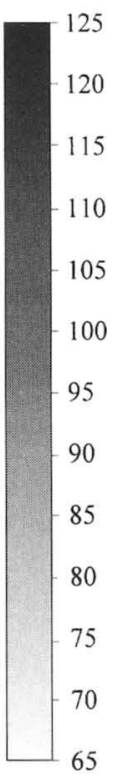

FiG. 3. Resistivity map of the Gallo-Roman site of Champcelée, obtained with 1-m-side towed square array ( Suilly-la-Tour, Nièvre, France): (a) general map without directional filtering, (b) part of block 2 after directional filtering, and (c) interpretation of the main anomalies. 
comprises a more limited number of poles (Sørensen and Pedersen, 1992; Sørensen, 1996). For investigations at depths greater than $5 \mathrm{~m}$ (Mounir, 1994), a long line of electrodes is the only realistic solution, but it generates difficulties when changing from one profile to the other and fixes the orientation of all arrays to the one of the profile. This can result in an important apparent anisotropy effect.

A theoretical study and a series of experiments (Panissod et al., 1997) led us to adopt a so-called Vol-de-canards configuration, a V-shaped multipole system with one transmitting dipole and a series of receiving dipoles, the length of which increases with their distance from the transmitter. This configuration has three advantages: (1) it reduces the effect of superficial geophysical noise on larger receiver dipoles, (2) several depths of investigation can be used without switching, which takes too much time on injection electrodes, and (3) the total size of the arrays remains limited to a value equivalent to that of the depth of investigation and the driving ability remains satisfactory. Two Vol-de-canard prototypes were developed, one with three receiving dipoles for the electrical method (Figure 6) and the other with two receiving dipoles for the electrostatic method and road applications (Figure 7).

\section{MUCEP EXPERIMENTS}

\section{Test site of Garchy}

The first experiment was undertaken on a test zone of the Centre de Recherches Géophysiques at Garchy, France. This zone is $170 \mathrm{~m}(\mathrm{E}-\mathrm{W})$ by $90 \mathrm{~m}(\mathrm{~N}-\mathrm{S})$ and comprises (Figure 8f) a sharp natural change of the depth of the sound limestone $(400 \mathrm{ohm}-\mathrm{m})$ from $0.22 \mathrm{~m}$ in the eastern part to $1.5 \mathrm{~m}$ in the western, covered by a conductive layer of $50-60 \mathrm{ohm}-\mathrm{m}$ (feature 1). Two typical parasites already existed in this area: a system of electrical and telephone mains (feature 2) of E-W direction laid on the ground surface and a single NE-SW electrical cable (feature 3 ) buried at $0.7 \mathrm{~m}$. Two artificial structures were installed: an L-shaped ditch dug in the sound limestone and refilled with the conductive layer material (feature 4) in the eastern part and a 10-m-long wall-shaped feature of $1 \times 1 \mathrm{~m}$

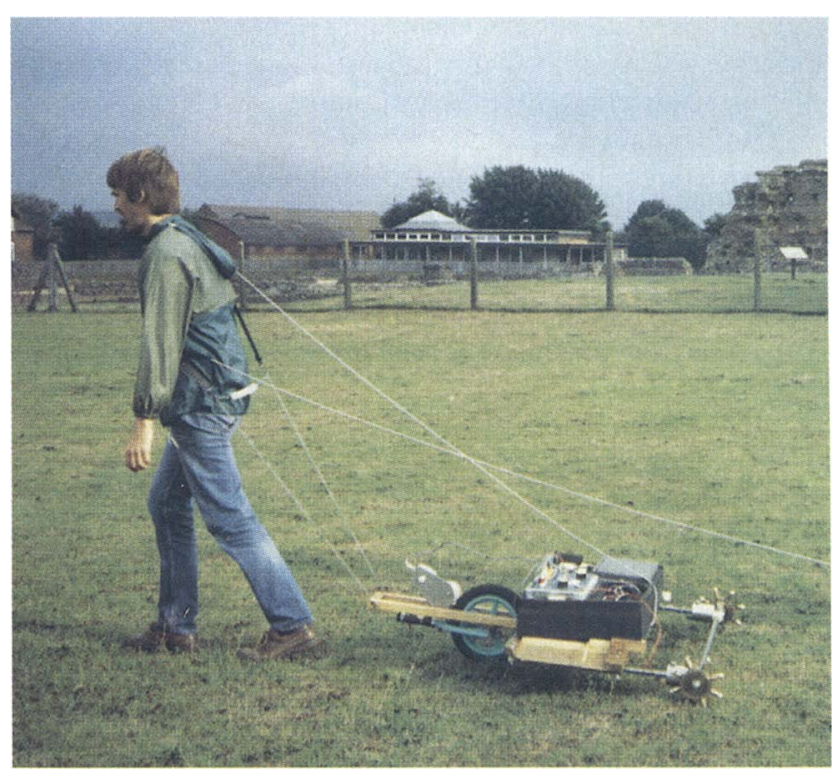

FIG. 4. Mobile pole-pole array pulled by a walking operator.

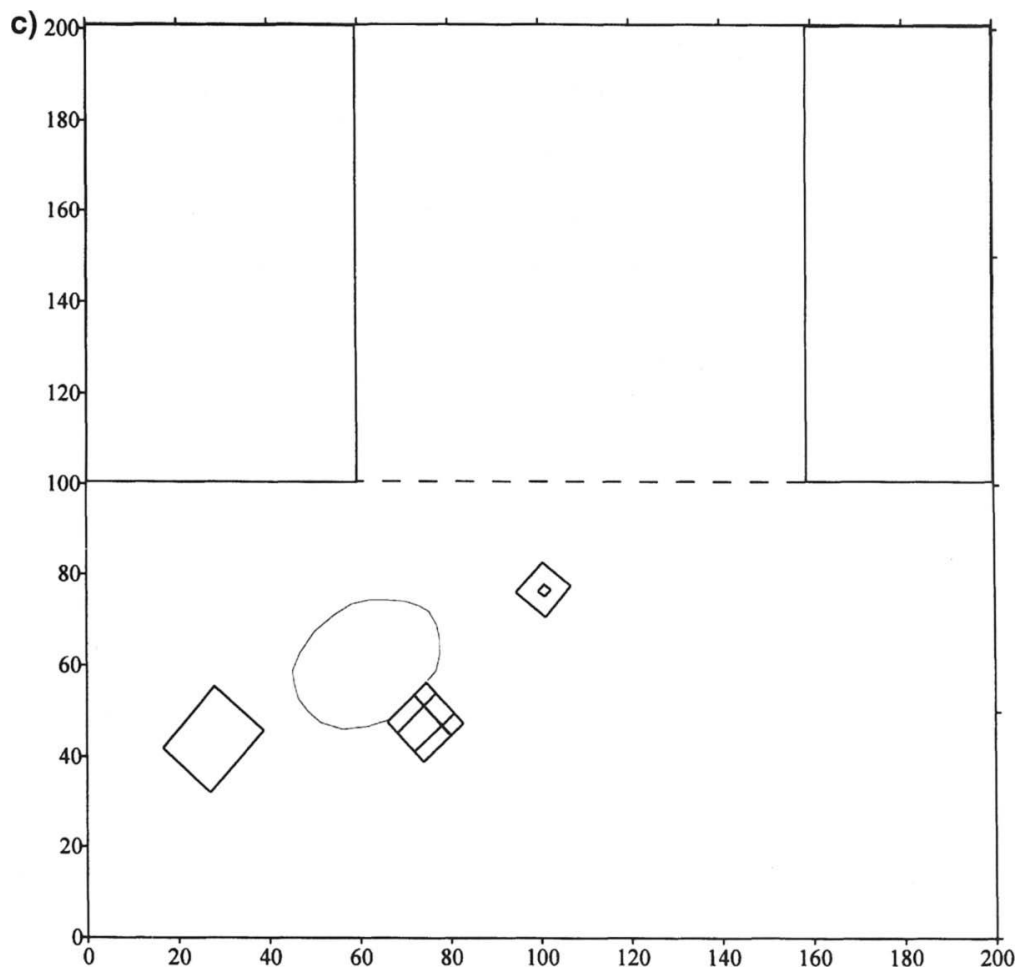

FIG. 3. Contd... 
cross-section built with the limestone extracted from the ditch (feature 5) with its roof at $0.2 \mathrm{~m}$ inside the conductive layer.

The apparent resistivity maps are presented in Figure 8. On all of them, the natural change from resistive to conductive area is very clear; but as the depth of investigation increases, the magnitude of the contrast reduces because of the influence of the limestone underneath. The $\mathrm{E}-\mathrm{W}$ electrical mains are responsible for the gap in the survey; however, neither these nor the other cable generates a resistivity anomaly. As could be foreseen from theoretical modeling, the wall corresponds to a clear resistive anomaly for the shallowest array (Figure 8a) to a reduced anomaly for the medium array (Figure $8 \mathrm{~b}$ ) and a reverse two extrema anomaly for the deepest (Figure 8c). The L-shaped ditch is very clear for the shallowest, and its anomaly reduces as the depth of investigation increases. Although less adapted to run on a grassy land, the electrostatic quadripole provided results (Figures $8 \mathrm{~d}, \mathrm{e}$ ) that agree well with the global resistivity values and anomalies.

\section{Experiment on Montbaron (Levroux, Indre, France)}

This archeological site is located on a large Jurassic plateau called Champagne bérrichonne; it corresponds mainly to a medieval settlement. It was surveyed at the request of A. Querrien (CNRS) with the electrical Vol-de-canards MUCEP with three different depths of investigation. The sampling step was $1 \mathrm{~m}$ between profiles, and the data were resampled at the same step along each profile. On the shallowest quadripole (Figure 9a) one can observe the remains of a motte or bailey castle, with a double donjon surrounded by a basse-cour which corresponds to a farmstead limited by a stony wall (feature 1). Other types of remains can be observed: to the north, a rectangular enclosure; to the south, a series of right-angle limits of the same orientation, the size of which may suggest an Iron Age date (features 2 ); to the west, long resistive strips corresponding to natural limestone outcrops (features 3 ). On the midsize quadripole (Figure 9b), the double central donjon is more marked: this suggests a significant thickness for its walls, while the limits of

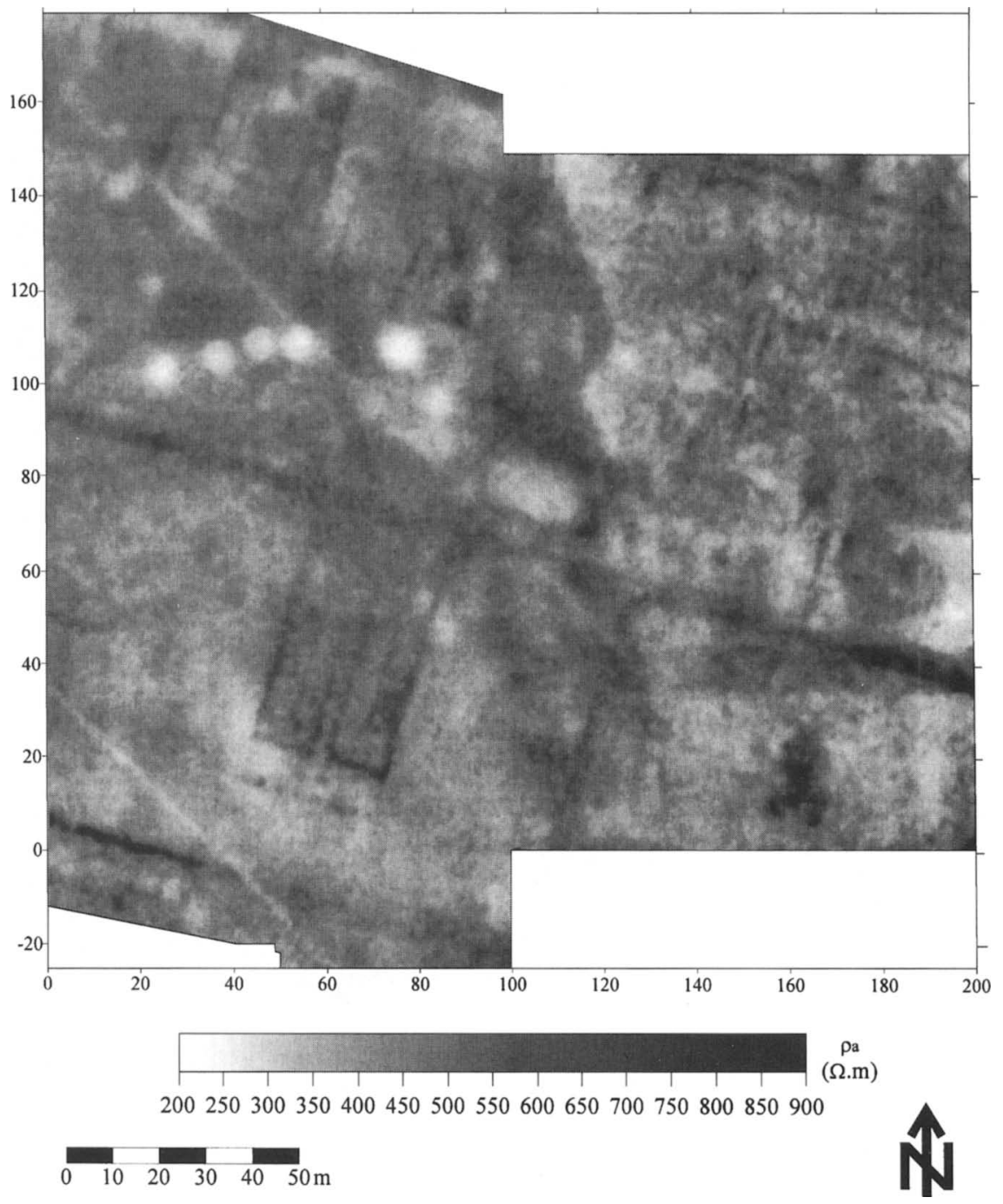

FIG. 5. Wroxeter (Shropshire, England) apparent resistivity map; mobile pole-pole array; $a=1 \mathrm{~m}$. 

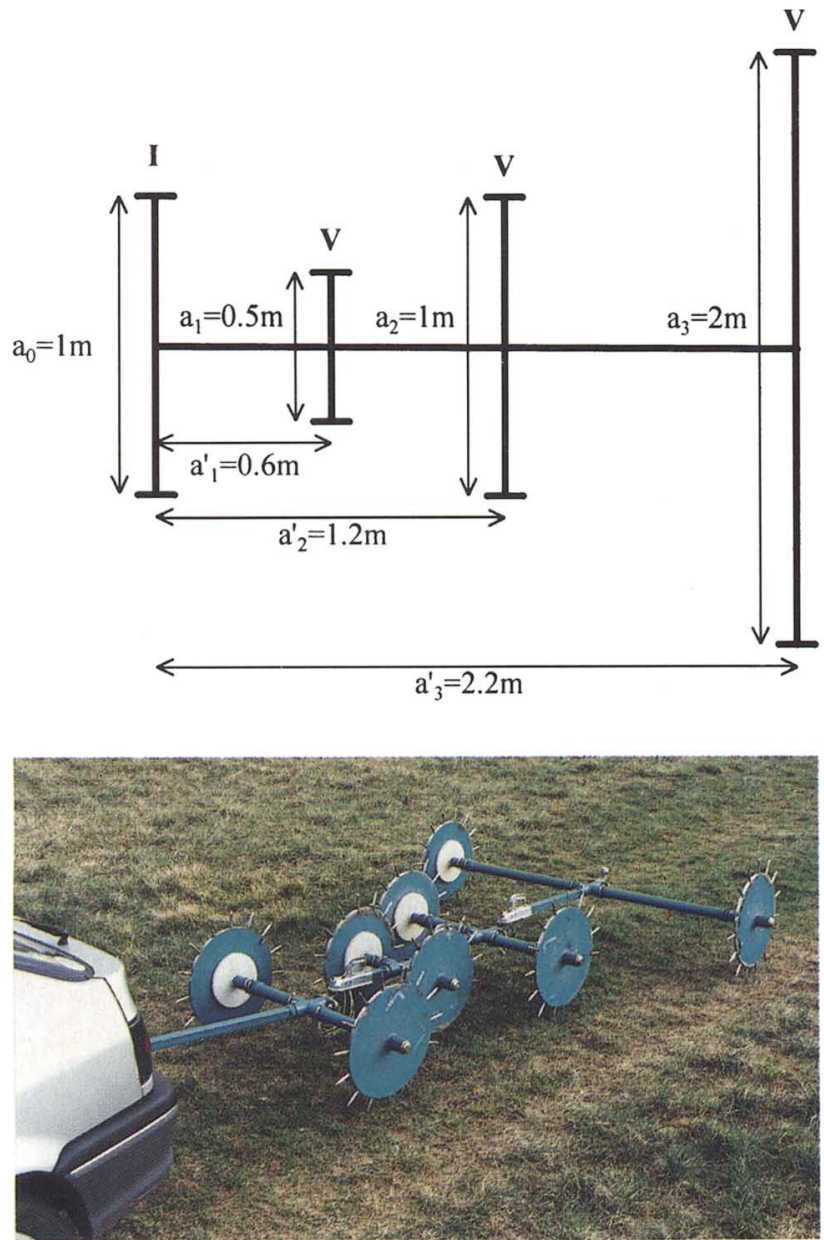

FIG. 6. Geometrical configuration of the electrodes in the electrical Vol-de-canards MUCEP (top) and the prototype (bottom).

the basse-cour and the enclosure correspond to less-apparent anomalies, suggesting these features are of limited thickness. On the deepest quadripole (Figure 9c) the anomalies generated by all archeological features are reduced and the geological noise resulting from the complex reef facies of the limestone becomes more apparent. The global resistivity value increases with the depth of investigation.

\section{CONCLUSION}

The electrical method is an interesting way to survey shallow grounds, even when metallic objects or features could disturb other types of measurements (magnetic, electromagnetic). The light pole-pole, square, and multipole towed arrays are very efficient tools for mapping the resistive features corresponding both to buried archeological remains and to superficial geological changes. This is very valuable for surveying ancient settlement at low cost without using invasive methods. The speed of data acquisition in the field is drastically increased by reference to the point-by-point measurement. The results presented in this paper emphasize the main advantages of the electrical and electrostatic methods: (1) they are insensitive to metallic disturbances, (2) they afford good sensitivity to resistive as well as conductive targets, (3) they allow simultaneous mea-
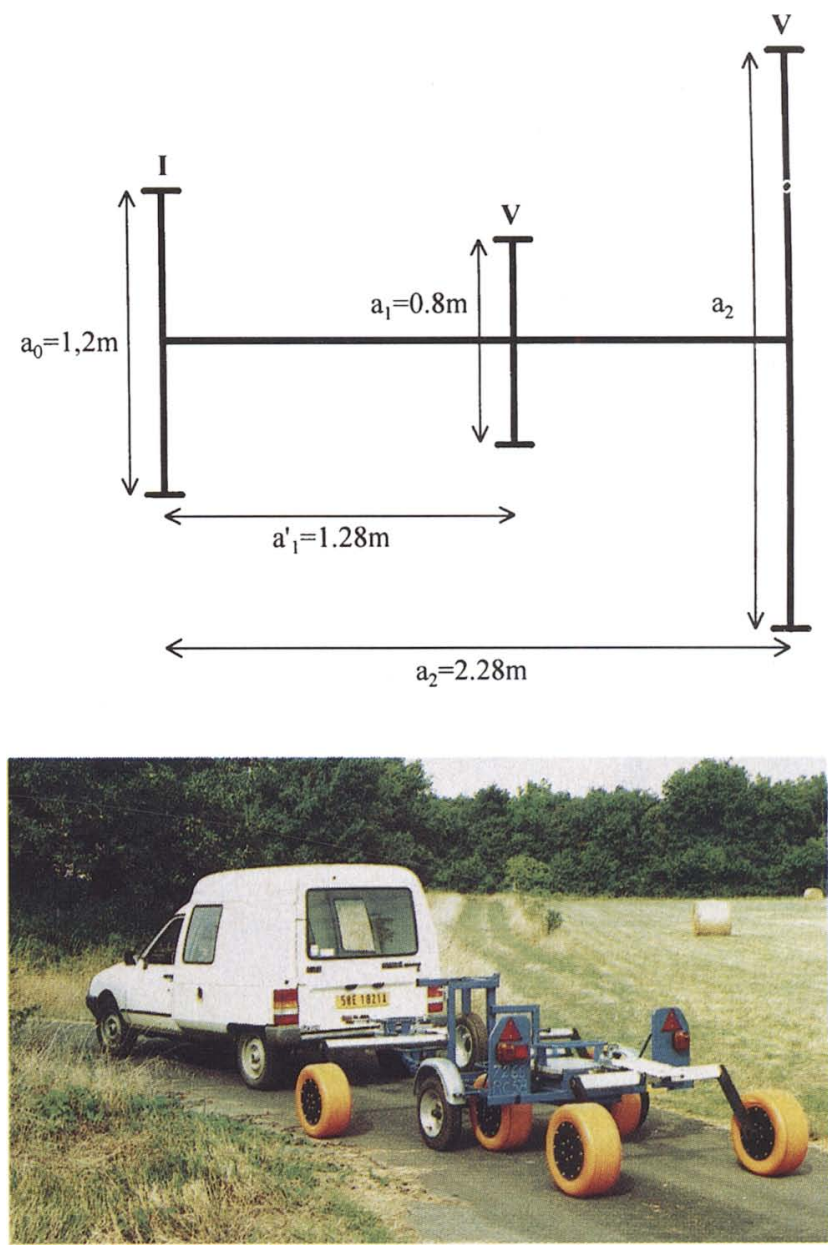

FIG. 7. Geometrical configuration of the poles in the electrostatic Vol-de-canards MUCEP (top) and the prototype (bottom).

surements over several depths of investigation, and (4) they can cover more than 2 ha/day with a $1-m$ sampling step. The different types of mobile arrays constitute a group of robust tools that delivers accurate, rich information on both natural soil and anthropogenic features.

\section{REFERENCES}

Dabas, M., Ducomet, G., Hesse, A., Jolivet, A., and Tabbagh, A., 1989, Intérêt de la cartographie de la résistivité électrique pour la reconnaissance du sol à grande échelle: Sciences du Sol, 27, 65-68.

David, A., 1995, Geophysical survey in archaeological field evaluation: Research and Professional Services Guideline $N^{\circ} 1$, English Heritage.

Grard, R., and Tabbagh, A., 1991, A mobile four-electrode array and its application to the electrical survey of planetary grounds at shallow depths: J. Geophys. Res., 96, 4117-4123.

Hesse, A., 1966, Perfectionnement des applications archéologiques de la prospection électrique: Comptes Rendus mensuels de la Société Préhistorique Française LXIII, 15-19.

Hesse, A., Jolivet, A., and Tabbagh, A., 1986, New prospects in shallow depth electrical surveying for archaeological and pedological applications: Geophysics, 51, 585-594.

Jolivet, A., 1992, Installation de prospection géophysique: Brevet Français 9110528 .

Martinaud, M., 1990, Intérets du dispositif bipôle C-P en prospection électrique mécanisée: Revue d'Archéométrie, 14, 5-16.

Martiré, O., 1996, Dispositif multi-électrodes en courant continu de canalisation et de surface: Conception et réalisation des équipements, mesures, interprétations: Thesis, Univ. of Paris.

Mounir, A., 1994, Application du quadripôle électrostatique à la 

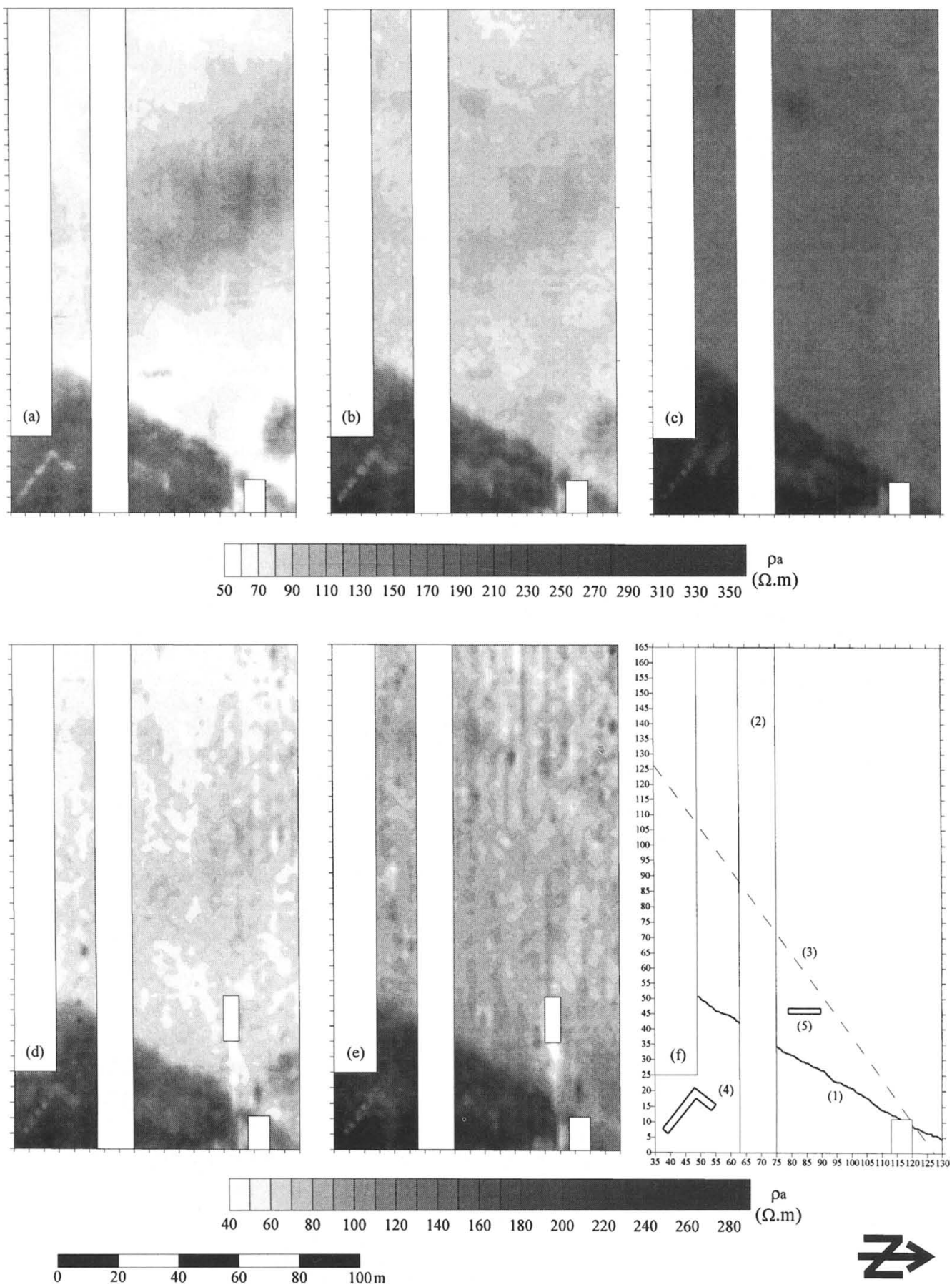

FIG. 8. Site presentation (f) and apparent resistivity maps obtained with electrical and electrostatic Vol-de-canards MUCEP arrays: (a) shallowest electrical quadripole, (b) medium electrical quadripole, (c) deepest electrical quadripole, (d) shallowest electrostatic quadripole, (e) deepest electrostatic quadripole.

prospection sur la gamme de profondeur 0-100 m: Thesis, Univ. of Paris.

Panissod, C., Dabas, M., and Tabbagh, A., 1997, A novel mobile multipole system (MUCEP) for shallow $(0-3 \mathrm{~m})$ geoelectrical investigation, the "Vol-de-canards" array: Geophys. Prosp., 45, 983-1002.

Sørensen, K., 1996, Pulled array continuous electrical profiling: First Break, 14, 85-90.

Sørensen, K., and Pedersen, F. F., 1992, Slaebe-geoelectrik: Miljominsteriet, skov-og naturstyrelsen, Kortlaegnins-serien, 29.
Tabbagh, A., 1992, Méthodes géophysiques appliquées à la prospection archéologique: Mémoire Soc. Géol. Fr., 161, 9-15.

Tabbagh, A., Hesse, A., and Grard, R., 1993, Determination of electrical properties of the ground at shallow depth with an electrostatic quadrupole: Field trials on archaeological sites: Geophys. Prosp., 41, 579-597.

Tabbagh, J., 1988, Traitement des données et élimination des valeurs erronées en prospection électrique en continu: Revue d'Archéométrie 12,1-9. 


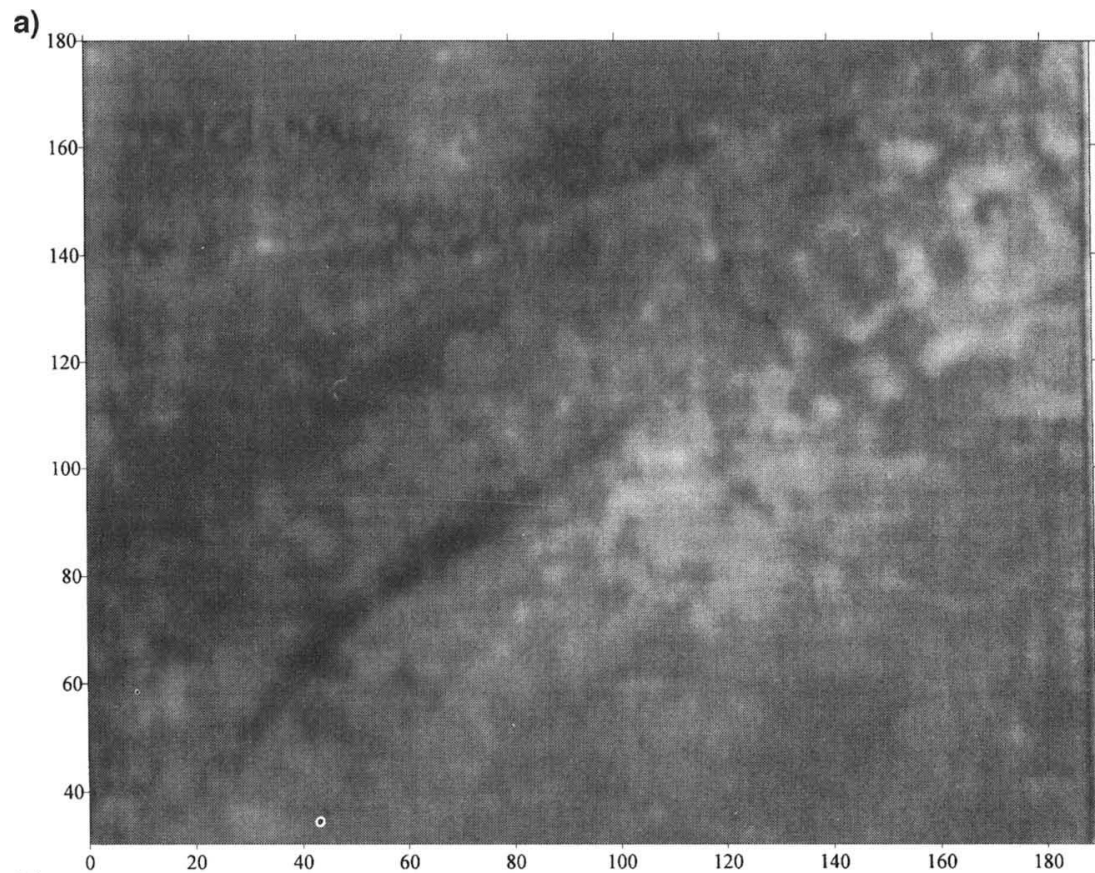

b)

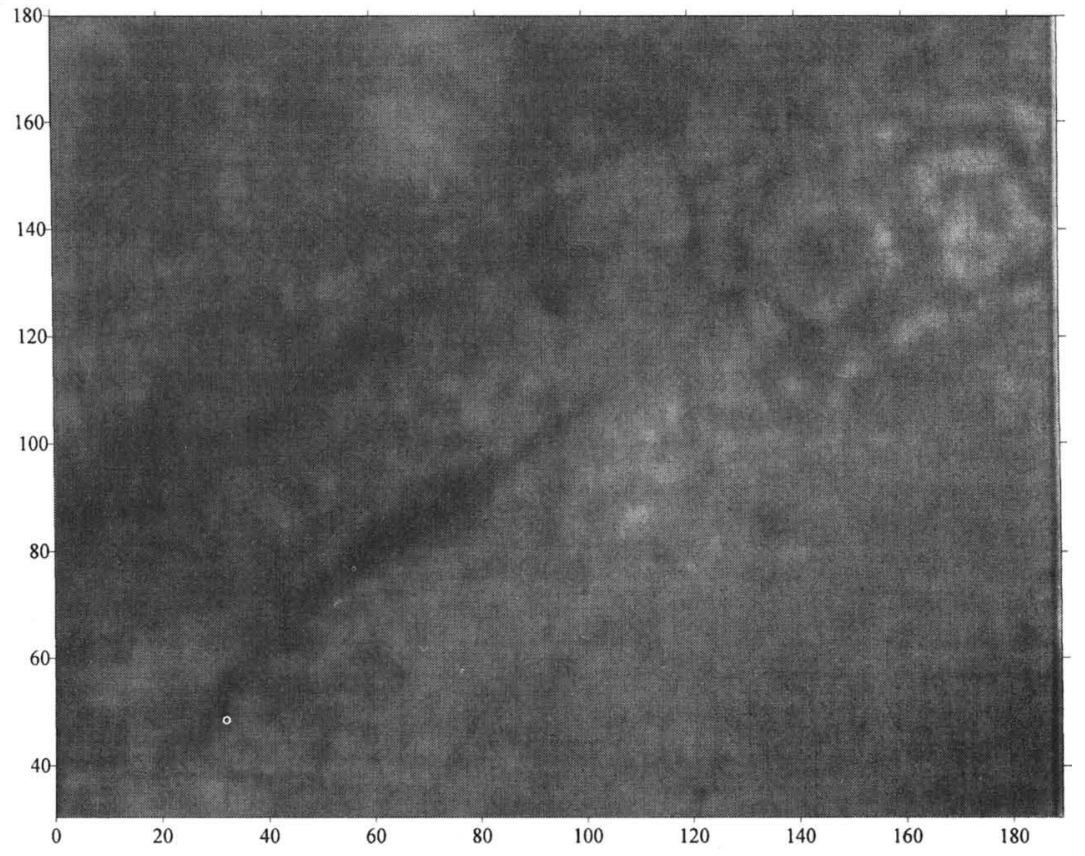

FIG. 9. Apparent resistivity maps of Montbaron (Levroux, Indre, France) archeological site: (a) shallowest electrical quadripole, (b) medium quadripole, (c) deepest quadripole, (d) interpretation of the main anomalies. 

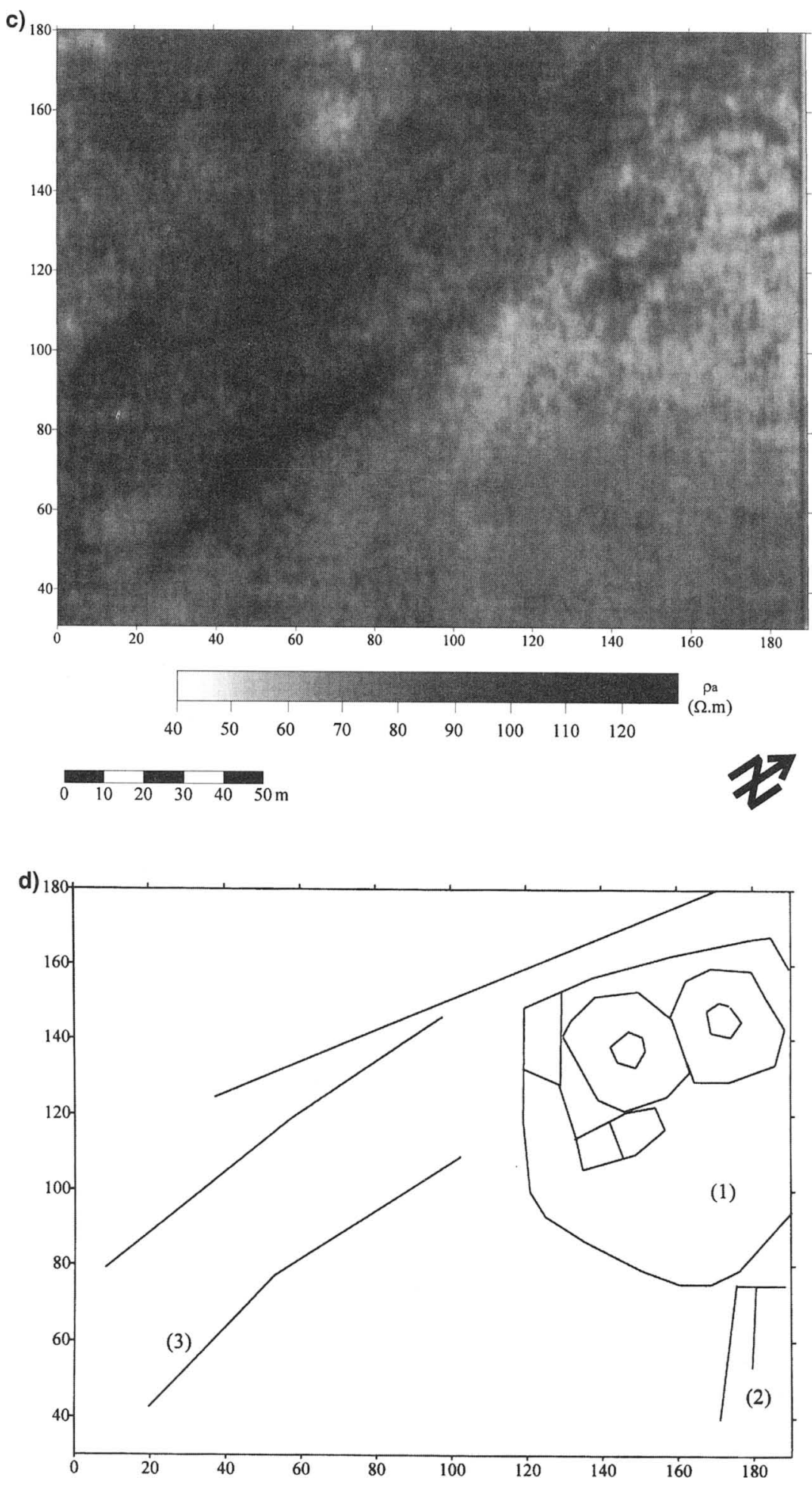

FIG. 9. Contd... 